NBSIR 84-2961

\title{
A Procedure for Tristimulus Color Measurements on Building Stone
}

Lawrence I. Knab

U.S. DEPARTMENT OF COMMERCE

National Bureau of Standards

National Engineering Laboratory

Center for Building Technology

Gaithersburg, MD 20899

October 1984

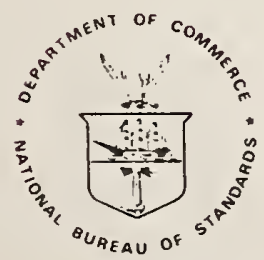

".S. DEPARTMENT OF COMMERCE 


\section{A PROCEDURE FOR TRISTIMULUS COLOR MEASUREMENTS ON BUILDING STONE}

Lawrence I. Knab

U.S. DEPARTMENT OF COMMERCE

National Bureau of Standards

National Engineering Laboratory

Center for Building Technology

Gaithersburg, MD 20899

October 1984

U.S. DEPARTMENT OF COMMERCE, Malcolm Baldrige, Secretary NATIONAL BUREAU OF STANDARDS. Emest Ambler. Director 



\section{INTRODUCTION}

As part of the National Acid Precipitation Assessment Program, the research goal of the Materials Effects Task Group is to assess the damage caused by acid deposition on selected building materials: including building stone. One of the ways this damage is being assessed is by exposing building stone at various outdoor exposure sites for ten or more years. The changes in properties, including color, of the exposed stone as compared to the unexposed stone will be measured and analyzed. Additional information, including the rationale for selection and a description of the stone briquettes used for the different stone types, is given in other reports (e.g. Reference 1 for Salem limestone).

Although there is an ASTM method (Reference 2) for instrument evaluation of color differences of opaque materials, there was no specific procedure for measuring color differences on exposed building stone. This report describes a procedure developed to measure color and color differences on biilding stone surfaces using a specific diffuse reflectance, tristimulus colorimeter. The colorimeter had three filters, was based on CIE standard illuminant C, had an angle of illumination of $0^{\circ}$ from the perpendicular (with light striking the sample at $90^{\circ}$ relative to the sample surface), and had an angle of viewing of $45^{\circ}$ from the perpendicular (with light returning at $45^{\circ}$ relative to the sample surface). The development of the procedure was based on color measurements taken on the surfaces of Salem limestone and Shelbourne marble prior to their exposure. Consultations with a statistician and a color metrologist were used as input in developing the procedure.

\section{COLORI METER AND STANDARD PANELS}

The colorimeter used was a Reflection Meter 670* (figure 1) used in conjunction with a Search Unit 610T* (figure 2), both manufactured by Seragen* (Photovolt*). Reasons for choosing this colorimeter include its availability and portability.

Prior to using, the colorimeter was serviced and calibrated by its manufacturer and the standard reflectance enamel panels, NBS Sets Nos. 72 and 6, were calibrated with Gardner* colorimeters, 2005 and 805 series respectively. After servicing, preliminary measurements comparing the readings of the Seragen colorimeter and a colorimeter from a different manufacturer indicated that the Seragen colorimeter was performing with a satisfactory accuracy (closeness to the true answer). Preliminary measurements indicated that the precision (repeatability about a given base line) of the Seragen colorimeter was within the limits of the nanufacturer's specification, when the procedure in this report was followed.

*Certain thanufacturer names, commercial equipment, instruments, or materials are identified in this report in order to adequately specify the experimental procedure. Such identification does not imply recommendation or endorsement by the National Bureau of Standards, nor does it imply that the materials or equipment identified are necessarily the best available for the purpose. 
It is recommended that, as the color data on both the unexposed and exposed stone are collected and analyzed, the Seragen colorimeter accuracy and precision be periodically determined. Also the standard reflectance panels should be recalibrated during the study, or at least at the end of the study. The procedure in this report should be evaluated and, if necessary, updated based on subsequent data analyses.

To insure consistency of results over the ten year or longer duration of the study, it is recommended that the same colorimeter (Seragen) be used for all measurements taken. The differing characteristics of different colorimeters which all reputedly measure the same quantities, precluded the development of a procedure which would apply to all sultable colorimeters. The procedure described in this report is specific to the colorimeter used. Procedures for other suitable colorimeters could also be developed. The details of those procedures for the other colorimeters, however, would most likely differ from the procedure given in this report.

If another colorimeter must be used, then a modification of the procedure in this report would be needed to provide at least a comparable level of accuracy and precision. Also a correlation between the Seragen colorimeter and any colorimeter replacing it would need to be established with both standard reflectance enamel panels and standard test stone surfaces (see discussion in last section - Equipment Repair or Modification or the Use of an Alternate Colorimeter). The procedure in this report is for color readings taken in a laboratory environment. Readings taken on stone briquettes in another environment, such as in their field exposure seats, would require modification to the procedure. For example, the stone surfaces in their field seats are at an angle relative to the horizontal as compared to the horlzontal position in the laboratory. This difference in angle could affect the response of the $610 \mathrm{~T}$ Search Unit.

The National Park Service has information on the handling, packaging, shipping, and characterization of the stone briquettes prior to their being measured for color, including subjecting the briquettes to a short term, constant, environment. After subjecting the briquettes to the short term environment, they were wrapped in aluminum foil, placed in sealed plastic bags, carefully packaged to prevent breakage and sent to the National Bureau of Standards (NBS). The briquettes were stored in an NBS laboratory in their sealed plastic bags. Prior to taking color readings, the briquettes were removed from their plastic bags and the aluminum foil was removed from the briquettes. After completing the color readings, each briquette was returned to the same plastic bag it was shipped in and the bag was then sealed.

\section{PREPARATION, WARMUP, AND SELECTION OF COLOR-STONE TYPE}

Follow the general operating instructions given in "Operating Instructions for Reflection Meter 670" - Reference 3, including the instructions in paragraphs 1.1 through 1.5 given in 1. SETTING UP THE INSTRUMENT on page 1241 . Use the standard scale of 100 units full scale (Normal Sensitivity, not High Sensitlvity) on the 670 Reflection Meter. The reflectance measurements are taken with the green, amber, and blue color filters. The plug which connects the 610T Search 
Unit and the 670 Galvanometer is to be snugly connected so that there is no change in reading when the cord of the $610 \mathrm{~T}$ Search Unit is moved, causing a force to be exerted on the plug. In this study, a weight was placed on the cord of the 610T Search Unit so that no force was exerted on the plug as the cord was moved while taking color readings.

Select the filter color (green, amber, or blue) and stone type (e.g., Salem limestone or Shelbourne Vermont marble) and use this color-stone type combination throughout the procedure in Steps 1 through 4 of this report. After completing the procedure for the first color-stone type combination on at most twelve stone briquettes which are to be exposed or have been exposed, follow the procedure of Steps 1 through 4 for the next color-stone type combination of at most twelve briquettes. The procedure is repeated until all color-stone type combinations are completed; that is, every stone briquette will have been measured with the green, amber, and blue filters. The order in which the color-stone type combinations are measured should be randomized as much as possible. The order of measuring the twelve or fewer briquettes within a color-stone type combination should also be randomized as much as possible. A statisician should be consulted when developing these randomization schemes.

When taking color readings, wear clean (washed) rubber gloves and be careful not to touch the exposed stone surface (arrow points to this surface - figure 2). Never place fingers or thumbs on color filters (figure 2). If a finger or thumb print does get on a filter, remove it by gently and carefully rubbing the filter surface with a lint-free, soft, disposable wipe, such as a Kimwipes* wipe. (The slight amount of moisture on the filter caused by "breathing" on the filter just prior to wiping may help remove the finger or thumb print). Be sure all particles (e.g•, dust) are first removed from the filters. Small particles can be removed by using a stream of purified compressed air, being careful not to cool down the filter, which could damage the filter or its mounting. When changing the lamp for the 610T Search Unit, follow directions on page 1245-46, paragraph 12.1 in Reference 3 and be sure all finger and thumb prints and foreign particles are removed from the lamp surface using a lintfree, soft, disposable wipe.

Be sure the 610 T Search Unit and 670 Reflection Meter are warmed up at least 30 minutes with the $610 T$ Search Unit vertical on a flat, clean, surface and with the light pointing down on the flat surface (face down). The color of the warm-up surface is not to be significantly different than the surface being measured. For example, do not use a black warm-up surface if measurements are to be taken on lighter colored stone. (A brown surface was used as a warm-up surface for the measurements taken in this report). Do not use standard reflectance panels as warm-up surfaces because of the possible damage due to heat build-up on the panel surfaces.

* Refer to footnote on page 1. 


\section{COLOR MEASUREMENT STEPS}

There is one equipment calibration step and two equipment check steps. The calibration step is to calibrate the equipment prior to taking color measurements, using standard reflectance panels. The first equipment check is to insure that the equipment is performing properly on standard reflectance panels and to detect a change that may have occurred in the calibration panel (e.g., fading). The second equipment check is to insure that the equipment is performing properly on the standard stone surfaces.

\section{Step 1}

Equipment Calibration Using Standard Reflectance Panels. Use a standard reflectance enamel panel from NBS Set No. 72 and use the color calibration values on the label affixed to the back of each panel. The color calibration values of the standard calibration panel chosen should match as closely as possible the stone color readings to be taken*. It is noted that the calibration panel used for the standard briquette may differ from that used for the briquettes to be exposed or the briquettes which have been exposed. In the case where more than one calibration panel is used, the order of using the panels is given in Step $2 \mathrm{~b}$.

Place the standard panel on a flat surface, coated side up (figure 3 ). Place the centering template (see figure 4) on the standard panel. The purpose of the centering template is to insure that the 610T Search Unit 11ght strikes the center of the standard panel. Select the filter color to be used - green, amber, or blue. Next place the 610T Search Unit in the hole in the centering template (figure 5). Using the sensitivity controls F and G (paragraph 2.2, Pg. 1241 - Reference 3), adfust the 670 Reflection Meter to the calibration value on the back of the panel for the filter color being used. Interpolate the needle reading to the nearest 0.1 unit $\left(e_{.} ., 61.2\right)$. To check for instrument drift*t, record repeated readings one minute apart unt11 at least four readings have been taken and the last two readings agree to within 0.2 units $(e . g ., 39.3,39.2$, $39.0,39.2$ ). If any drift has occurred, adjust the $F$ and $G$ sensitivity controls such that the 670 Reflection Meter matches the calibration value on the panel back (see table 1). Resetting the instrument to the calibration value is done to keep the instrument calibrated as closely as possible to the correct value when taking subsequent readings on other surfaces (1.e., panels from set No. 6 , standard briquettes, and briquettes which are to be exposed or have been exposed).

* Trial color readings on stone briquetts should be taken - see discussion in Steps $3 \mathrm{~b}$ and $4 \mathrm{~b}$.

** The drift criterla were empirically determined to be satisfactory. Compliance with these criteria indicates that the instrument has stabilized. 
Equipment Check Using Standaro Reflectance Panels.

Step 2a. The "check" panels from NBS Set No. 6 are generally similar to the calibration panels in NBS Set No. 72. The panels in Set No. 6 are used to:

(1) Insure that the equipment is performing properly on standard reflectance enamel panels

(i1) detect a change (e.g., fading) in the calibration panels

(iii) serve as a backup set of calibration panels throughout the study.

After completing the calibration process with a panel from Set No. 72, select for the chosen color, the "check" panel from Set No. 6 with a calibration value which most closely agrees with the calibration value from the panel used from Set No. 72. Note that for both Set Nos. 72 and 6, usually the panel number $(\mathrm{e} . \mathrm{g} \cdot, 40)$ corresponds roughly to the calibration values on the back of the panels for the three colors. For example, panel 40-72 (40 is the panel number, 72 is the set number) and panel 40-6 (40 is panel number, 6 is set number) agree most closely. Place the centering template on the "check" panel and then place and center the 610T Search Unit on the "check" panel, as when using the standard reflectance panels shown 1n figures 3 to 5 .

Take at least two repeated readings one minute apart until the last two readings agree within 0.2 units. If the average of these last two readings agrees within 1.5 units with the calibration value on the back of the "check" panel, then the equlpment is considered to be performing satisfactorily (see table 1). If a difference of more than 1.5 units exists, then repeat the entire procedure beginning at Step 1 .

Step 2b. Return the $610 \mathrm{~T}$ Search Unit to the calibration panel used in Step 1, using the centering template. Take at least two repeated readings one minute apart unt 11 the last two readings agree within 0.2 units. If the difference between the average of the last two readings and the calibration value on the back of the calibration panel exceeds 1.5 units (see table 1) repeat the entire procedure, beginning at Step 1. If drift has occurred (less than or equal to 1.5 units) from the callbration value and readings are about to be taken on a standard briquette, adjust the $F$ and $G$ sensitivity controls such that the 670 Reflection Meter matches the calibration value on the back of the panel (table 1). Resetting the instrument to the calibration value is done to keep the instrument callbrated as close as possible to the correct value when taking subsequent readings on the standard briquette.

If for a given color, it is required to use more than one calibration panel, repeat Steps 1 and 2 for each calfbration panel used. As an example, for briquettes to be exposed or which have been exposed, if panel 20-72 was used as the calibration panel in Step 1, then 20-6 would be used as the "check" panel in Step 2. If for the standard briquette, pane1 40-72 was 
used as the calibration panel in Step 1 , then 40-6 would be used as the "check" panel in Step 2. Note that Steps 1 and 2 should be performed last for the panels used with the standard briquette so that the equipment has been calibrated on the proper panel prior to taking color readings on the standard briquette in Step 3.

Equipment Check Using A Standard Stone Briquette. This step is to insure that the equipment is performing properly on the surface of a standard briquette of the stone type (e.g., Salem Limestone or Shelbourne Vermont marble) being used.

Readings on the standard briquette are taken after the equipment calibration* and check steps are completed (Steps 1 and 2). The procedure is as follows, using the color-stone type combination selected and using a standard briquette of the same stone type selected.

Step 3a. The color readings are taken at four positions on the exposed stone surface as shown in figure 6. A briquette template is used to position the $610 \mathrm{~T}$ Search Unit on the stone surface. Place the standard briquette on a flat, clean, horizontal surface and orient the standard briquette as shown in figure 2, with the finished (exposed) surface facing up (arrow points to finished surface) and with the label on the bevelled surface facing the operator. Attach the briquette template to the 610T Search Unit as shown in figure 7 by hand tightening the two knurled screws while keeping the $610 \mathrm{~T}$ Search Unit vertical with the light pointing down. Attaching the template should take about 15 to 20 seconds. Locate the $610 \mathrm{~T}$ Search Unit on position 1 by gently placing the flat 1 in. by 2 in. template surface (figure 7 ) against the non-bevelled stone surface (figure 2 ) so that the 1 inch edge (figure 7) of the template coincides with the 2 inch corner edge formed by the intersection of the bevelled and non-bevelled stone surfaces as shown in figures 2 and 6 . When the $610 \mathrm{~T}$ Search Unit is positioned, record repeated readings one minute apart until at least four readings have been taken and the last two readings agree within 0.2 unit (table 2). Then move directly to position 2, maintaining the 610T Search Unit vertical - the total time to move should be about 5 seconds. Position 2 is found similarly to position 1, by matching the appropriate 1 inch template edge (figure 7) with the 2 inch stone corner edge (see figures 6 and 8 ). Take at least two repeated readings one minute apart until the last two readings agree within 0.2 unit (e.g., $60.5,60.3$ or $60.5,60.2$, 60.0 ) and then move directly to position 3 (figures 6 and 9). Position 3 is found similarly to positions 1 and 2 - by matching the appropriate 1 inch template edge with the 2 inch stone corner edge. Use the same reading

* Be sure the equipment was calibrated using the calibration panel from Set No. 72 with a calibration value which most closely agrees with the standard briquette color readings (see discussion in Step $3 b_{.}$) 
process at position 3 as used in position 2. Then move directly to position 4 (figures 6 and 10 ), again using the reading process used in positions 2 and 3. Position 4 is found similarly to the other three positions, that is, by matching the appropriate 1 inch template edge with the 2 inch stone corner edge. After position 4, move directly back to position 1 on the standard briquette, again using the reading process of positions 2,3 and 4. The average of the final (taken after position 4) last two readings at position 1 must agree within 1.0 unit of the average of the initial (taken prior to position 2) last two readings at position 1 (see table 2). If more than 1.0 unit difference exists, the standard briquette readings must be retaken, by repeating the entire procedure starting at Step 1 . If no more than 1.0 unit of difference exists and the color readings agree satisfactorily* with previous** readings (table 3 ), then the color readings for the standard briquette using the selected filter color are completed (see table 2), provided the instrument drift is acceptable as given in Step $3 \mathrm{~b}$ below.

Step 3b. The drift is to be checked by removing, in about 10 seconds or less, the briquette template from the 610T Search Unit, while keeping the unit vertical with the light pointing down. After removal of the template, immediately place the 610T Search Unit on the calibration panel used to calibrate the equipment, using the centering template. Record repeated readings one minute apart until at least two readings have been taken and the last two readings agree within 0.2 units (table 2 ). If the average of these last two readings with the $610 \mathrm{~T}$ Search Unit on the calibration panel does not differ by more than 1.5 units from the calibration value on the back of the calibration panel, the standard briquette readings are considered satisfactory (see table 2). If, however, there is more than 1.5 units difference, the standard briquette readings are not satisfactory and must be redone by repeating the entire procedure beginning at step 1 .

After taking the color readings on the standard briquette, the readings should be checked to see that they generally agree with the color reading of the standard reflectance enamel panel (Set No. 72) used to calibrate the equipment in Step 1 . That is, the standard panel having a calibration color reading which most closely agrees with the standard briquette color readings is to be used. For example, the green color readings in table 2

* If questions arise as to what is "satisfactory", a statistician should be consulted. If satisfactory agreement with table 3 is not obtained, then it needs to be determined whether the lack of agreement is due to (i) the equipment performing improperly, (ii) a change in stone color (which could occur, for example, during long term storage), or (i1i) a change in the calibration panel (e.g., fading).

** Initial baseline readings need to be taken on standard briquettes for each stone type prior to taking readings on exposed briquettes of the same stone type. See, for example, table 3. 
ranged from 45 to 46, generally agreeing with the 39.96 value on the back of the calibration panel, 40-72. (There is no 50-72 panel, so 40-72 was the appropriate panel choice). To help match the color value of the calibration panel with that of the color readings of the stone, trial readings on the standard briquette should be taken prior to beginning the procedure.

Step 4

Exposed Briquette Color Readings. Color readings are taken on stone briquettes which either have been exposed or are to be exposed at the field sites - these briquettes are called "exposed". After completing the equipment calibration and equipment checks on a standard panel(s) and a standard briquette, the color readings on the exposed briquettes are taken as follows:

Step 4a. Start by calibrating the equipment using the calibration panel from Set No. 72 which has a calibration color value which most closely agrees with the exposed briquette color readings. (Repeat only Step 1 see table 4). Color readings on the first exposed briquette of the color stone type combination (e.g•, green - Salem limestone) selected are taken in the same way as for the standard briquette (follow step 3a, except ignore the requirement that the readings are to agree with previous standard briquette readings). That is, the orientation, location of the finished (exposed) surface, the 610T Search Unit positions 1 through 4 , and the process and acceptance criteria of taking color readings at positions $1,2,3,4$, and then again at position 1 , are the same for the first exposed briquette measured and the standard briquette. In particular, be sure that (a) the last two readings at a given position agree within 0.2 units and (b) the average of the final (taken after position 4) last two readings at position 1 agree within 1.0 unit of the average of the initial (taken prior to position 2) last two readings at position 1 (table 4). If more than 1.0 unit of difference exists, the exposed briquette readings must be retaken by repeating all steps of the procedure, beginning at Step 1. If no more than 1.0 unit of difference exists, the readings on the first exposed briquette are satisfactory. Table 4 shows sample readings for the first exposed briquette.

To measure the second exposed briquette of the same color-stone type combination, move directly from position 1 of the first (measured) exposed briquette to position 1 of the second (unmeasured) exposed briquette and repeat the process of taking at least two readings one minute apart and moving to the next higher numbered position when the last two repeated readings agree within 0.2 units. On the second exposed briquette, move from position 1 to 2 to 3 to 4 and back to 1 (table 4 ). As with the first exposed briquette, the average of the final (taken after position 4) last two readings at position 1 must agree within 1.0 unit of the average of the initial (taken prior to position 2) last two readings at position 1 (table 4). If a difference of more than 1.0 unit exists, the readings are not acceptable and must be retaken, repeating all steps of the procedure, starting at Step 1. The measurement procedure and acceptance criteria for 
the third exposed briquette of the same color-stone type combination are the same as for the second exposed briquette (see table 4 ).

Step 4b. At the end of measuring at most three exposed briquettes, or when 45 minutes of time has elapsed from when the $610 \mathrm{~T}$ Search Unit was last on the standard calibration panel (Set No. 72), whichever occurs first, remove the $610 \mathrm{~T}$ Search Unit from the briquette template (keeping the unit vertical with the light pointing down and taking about 10 seconds or less) and place the 610T Search Unit, using the centering template, on the standard panel used to calibrate the equipment (see Step 4a). To check for instrument drift, record repeated readings one minute apart until at least four readings have been taken and the last two readings agree to within 0.2 units. If the average of these last two readings with the 610T Search Unit on the calibration panel does not differ by more than 1.5 units from the value on the back of the calibration panel, the exposure briquette readings are considered satisfactory (table 4). If, however, there is more than 1.5 units difference, the readings on the exposure briquettes (at most three briquettes) are not satisfactory and must be redone by repeating the entire procedure, beginning at Step 1 with the first briquette. If drift of less than or equal to 1.5 units has occurred, adjust the $F$ and $G$ sensitivity controls such that the 670 Reflection Meter reads the correct calibration value (see table 4).

After completing the first set of at most three exposure briquettes for the same color-stone type combination, measure at most three additional sets of the same color-stone type combination, with each set containing at most three exposure briquettes.

The same procedure and acceptance criteria are to be used for the additional sets as for the first set. Continue until color measurements on the exposure briquettes are completed or until at most twelve (four sets of three) exposure briquettes are measured for the same color-stone type combination. After completing the color readings on the last set of exposure briquettes measured, including checking the instrument drift, an equipment check using the panel(s) fron Set No. 6 is to be performed as described in Step 2. Finally, an equipment check using the standard briquette surface is to be performed as described in Step 3. If the equipment checks based on the panel(s) from Set No. 6 or the standard briquette are unsatisfactory according to the specifications previously given, then the color readings on all the exposed briquettes (at most twelve) taken with the same colorstone type combination are suspect and must be retaken, repeating the entire procedure, beginning at step 1.

As the color readings are taken on the exposed briquettes, the readings should be checked to see that they generally agree with the color reading of the standard reflectance enamel panel used to calibrate the equipment. That is, the standard panel having a calibration color reading which most closely agrees with the exposed briquette color readings is to be used. For example, the green color readings in table 4 ranged from 41 to 45, generally agreeing with the 39.96 value on the back of the callbration panel, 40-72. To help match the color value of the calibration panel 
with that of the color readings of the stone, trial color readings on the exposed briquettes should be taken prior to beginning the procedure. When Steps 1 through 4 are completed according to specification, the color measurements for at most twelve briquettes are acceptable for the selected color-stone type combination (e.g., green - Salem limestone).

The average of the last two readings at each of the stone briquette surface positions 2,3 , and 4 is to be used as the color reading value at that position. The average of the final (taken after position 4) last two readings and the initial (taken prior to position 2) last two readings at position 1 is to be used for the color reading value at position 1 (see table 4).

\section{EQUIP MENT REPAIR OR MDDIFICATION OR USE OF AN ALTERNATE COLORIMETER}

If any equipment repairs or modifications have been made, including a lamp or photocell replacement in the 610T Search Unit, or if another colorimeter needs to be used, a check should be made to determine if the base line of color measurements has changed. This determination can be made by correlating the color measurements of the repaired or modified equipment or of the alternate colorimeter with the original equipment using standard enamel reflectance panels and standard briquette stone surfaces. Due to the many factors affecting the diffuse reflectance response of a colorimeter, it is recommended that an expert in color metrology and colorimeter performance be consulted when making this determination.

Several potential problems are discussed below:

\section{a. Translucence}

Preliminary measurements have indicated that the Shelbourne Vermont marble is translucent. The diffuse reflectance response of a colorimeter on a translucent surface is affected by the geometric configuration of the colorimeter.

The "light spot" (image size of 1ight, about 5/8 in., emitted from the 610T. Search Unit on the surface being sampled) should be monitored for a change in size and/or location throughout testing, particularly when replacing a lamp or if the 610T Search Unit is accidentally jarred or dropped. A major change in the "light spot" should be visually evident (see paragraph 12.1, pg. 1245-46, Reference 3) and probably would be detected by a change in the readings of the Vermont marble standard briquette (C16-21).

The effect of translucence would also need to be taken into account when using an alternate colorimeter with a geometric configuration different than that of the $610 \mathrm{~T}$ Search Unit.

b. Additional Stone Types

Standard briquettes need to be used for each additional stone type studied. 


\section{c. Fluorescence}

If an additional stone type is used which is fluorescent (preliminary tests showed that neither the Salem limestone nor the Shelbourne Vermont marble are fluorescent), then equipment repair or modifications or the use of an alternate colorimeter which would change the equipment performance for fluorescent stone samples would need to be taken into account.

\section{REFERENCES}

1. Ross, M. and Knab, L. "Selection, Procurement, and Description of Salem Limestone Samples Used to Study Effects of Acid Rain," NBSIR 84-2905, July, 1984.

2. "Standard Method for Instrumental Evaluation of Color Differences of Opaque Materials" ASTM D2244-79.

3. "Operating Instructions for Reflection Meter 670," Photovolt-Seragen Diagnostics, P.0. Box 1210, Indianapolis, Indiana, 46206.

\section{Acknowledgements}

This effort was funded by the National Park Service through Ms. Susan Sherwood. The author wishes to acknowledge Dr. James Filliben of the Statistical Engineering Division at NBS for his statistical consultation and Dr. Jack Hsia of the Radiometric Physics Division, also at NBS, for his color metrology input. 
TABLE 2. Equipment check using standard stone briquette - sample readings (not to be used as data)

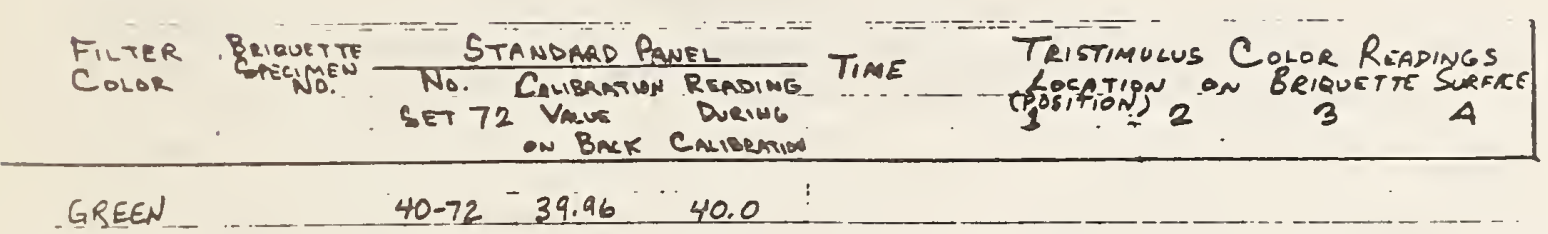

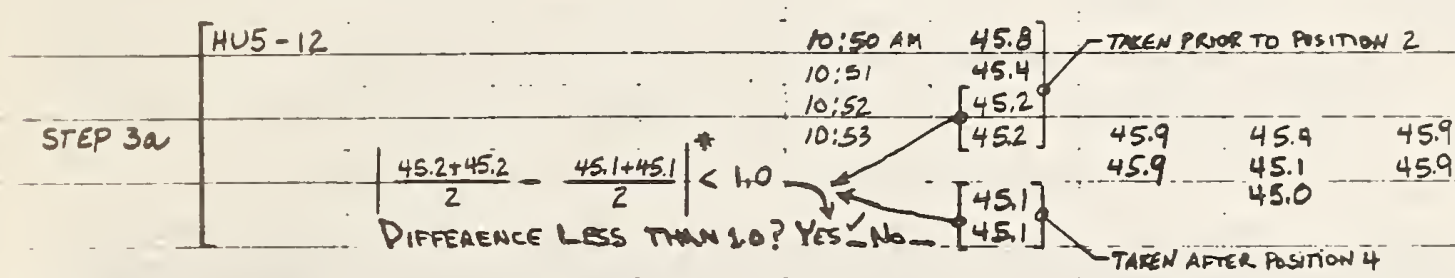

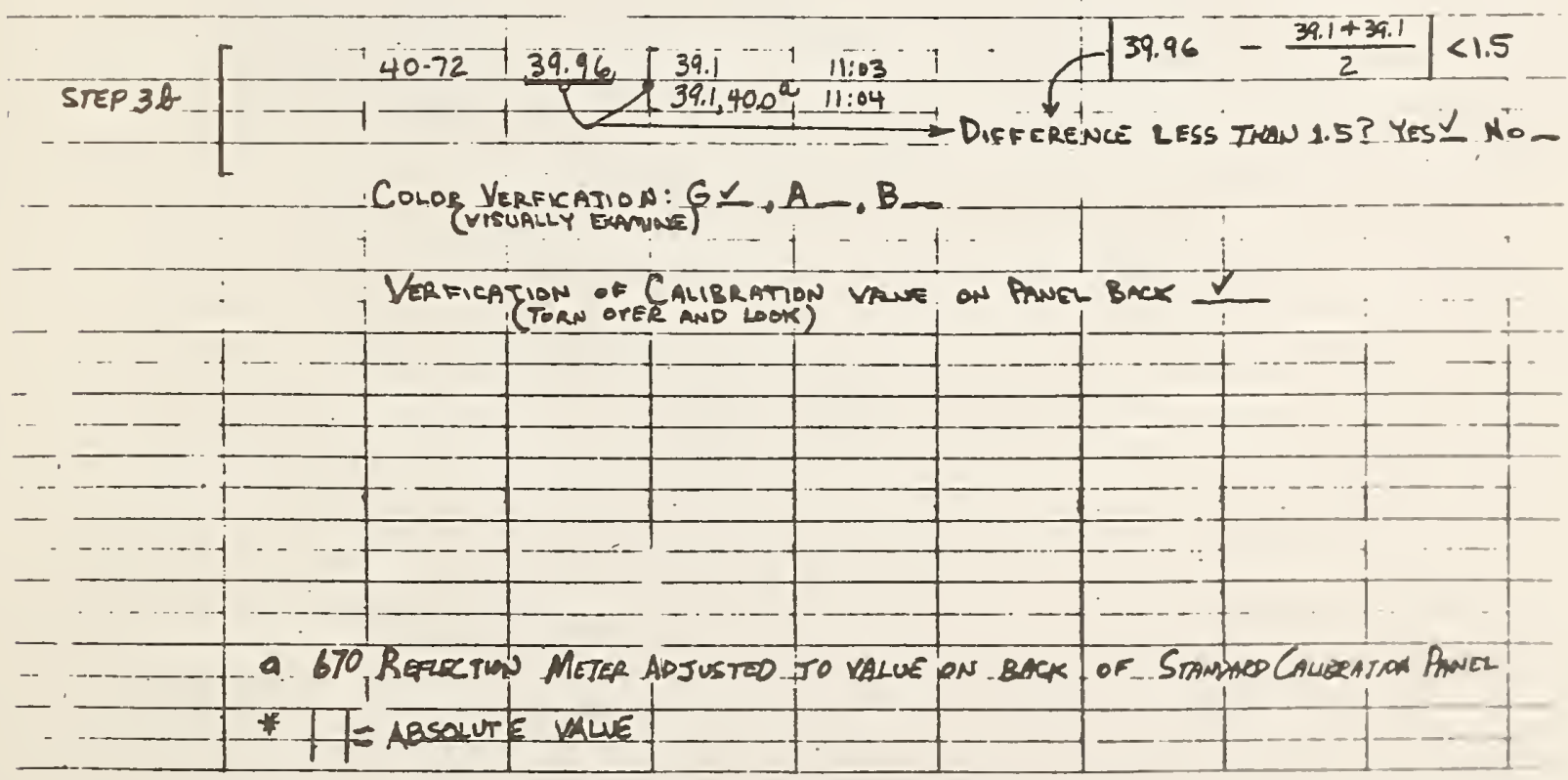


Table 3a. Color Measurements Using Standard Briquette HU5-12 (Salem Limestone)

\begin{tabular}{|l|c|c|c|c|c|c|c|c|}
\hline \multirow{2}{*}{$\begin{array}{l}\text { Filter } \\
\text { Color }\end{array}$} & \multicolumn{7}{|c|}{ Positions } \\
\cline { 2 - 9 } & \multicolumn{2}{|c|}{1} & \multicolumn{2}{|c|}{2} & \multicolumn{2}{|c|}{3} & \multicolumn{2}{c|}{ Max } \\
\hline Green & 45.0 & 45.3 & 45.9 & 46.0 & 45.0 & 45.6 & 45.5 & 46.0 \\
\hline Amber & 48.9 & 49.0 & 49.3 & 49.8 & 49.0 & 49.0 & 49.4 & 49.8 \\
\hline Blue & 37.0 & 37.2 & 37.9 & 38.0 & 37.1 & 37.4 & 37.9 & 38.0 \\
\hline
\end{tabular}

* Minimum and maximum color readings taken in May and June of 1984 when briquettes were measured prior to installing at four exposure sites. See original data sheets (National Park Service, c/o Ms. Susan Sherwood) for further detail. 
Table 3b. Color Measurements Using Standard Briquette C16-21 (Shelbourne Vermont Marble)

\begin{tabular}{|l|c|c|c|c|c|c|c|c|}
\hline \multirow{2}{*}{$\begin{array}{l}\text { Filter } \\
\text { Color }\end{array}$} & \multicolumn{7}{|c|}{ Positions } \\
\cline { 2 - 9 } & \multicolumn{2}{|c|}{1} & \multicolumn{2}{|c|}{2} & \multicolumn{2}{|c|}{3} & \multicolumn{2}{c|}{4} \\
\hline Green & 67.2 & 67.8 & 72.6 & 73.0 & 72.0 & 73.0 & 69.8 & 70.0 \\
\hline Amber & 67.1 & 67.3 & 72.9 & 73.2 & 72.2 & 73.0 & 69.6 & 70.0 \\
\hline Blue & 64.5 & 65.0 & 70.2 & 71.8 & 71.1 & 72.0 & 68.1 & 68.8 \\
\hline
\end{tabular}

* Minimum and maximum color readings taken in May and June of 1984 when briquettes were measured prior to installing at four exposure sites. See original data sheets (National Park Service, c/o Ms. Susan Sherwood) for further detail. 
TABLE 4. Exposed briquettes - sample readings (not to be used as data)

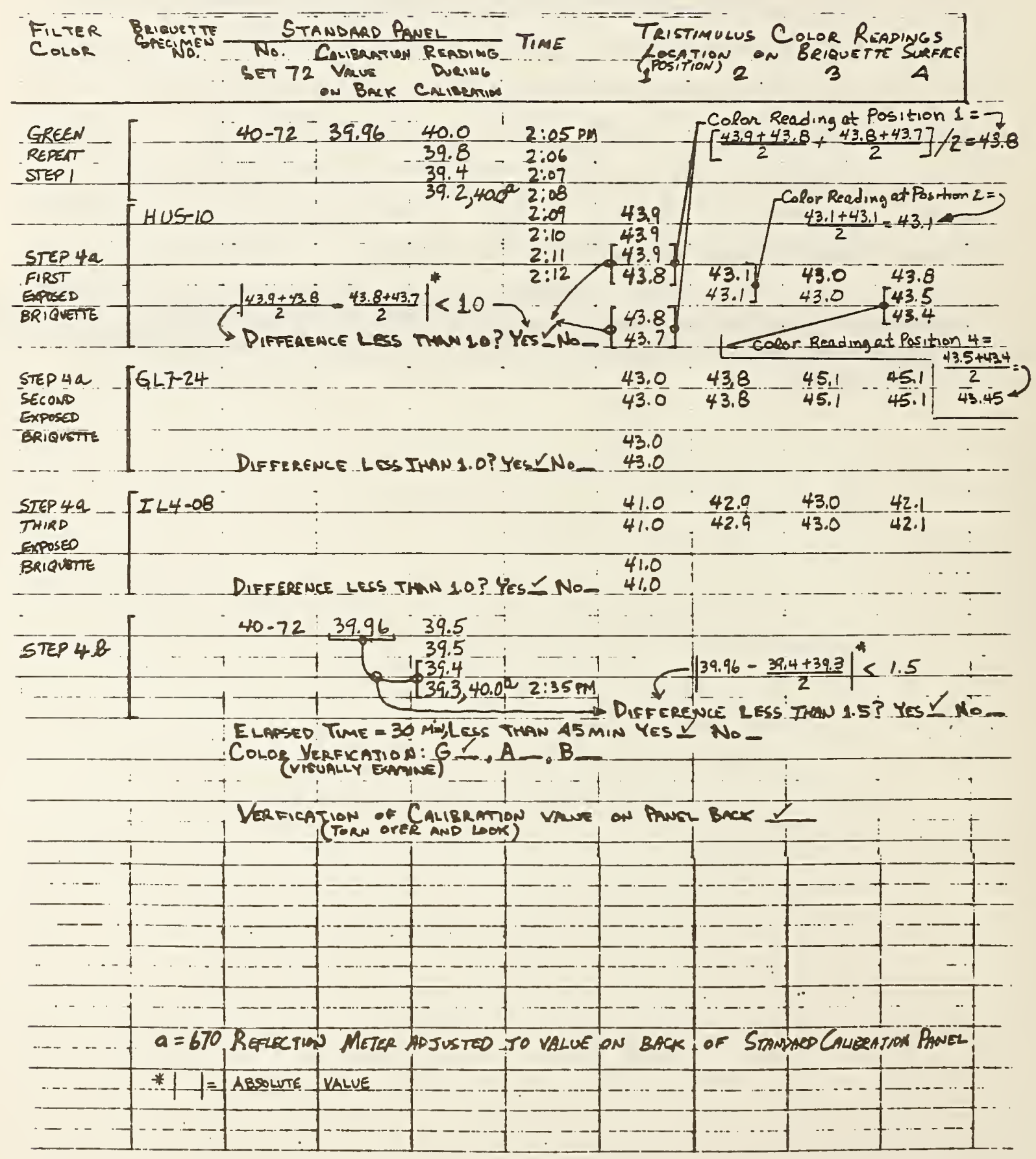




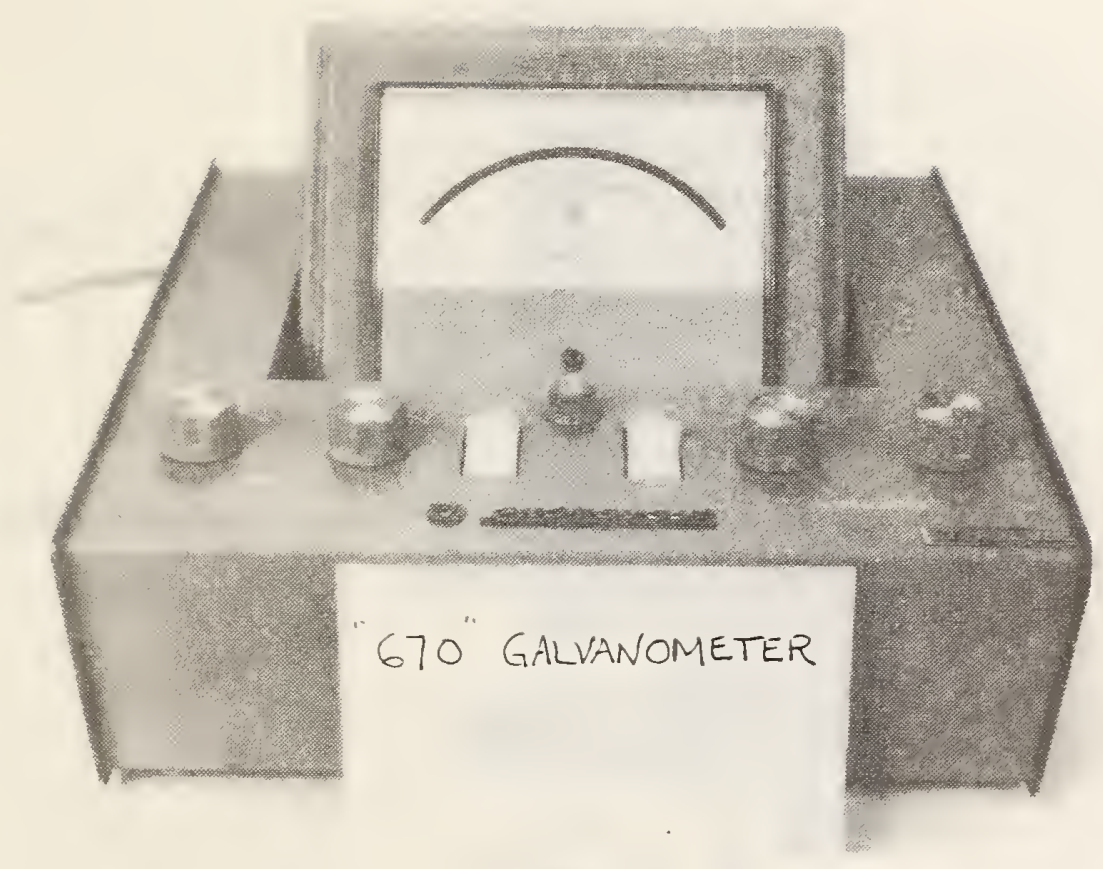

FIGURE 1. Reflection Meter 670, galvanometer used to take color measurements. 
2 inch corner edge formed by intersection of bevelled and non-bevelled stone surfaces

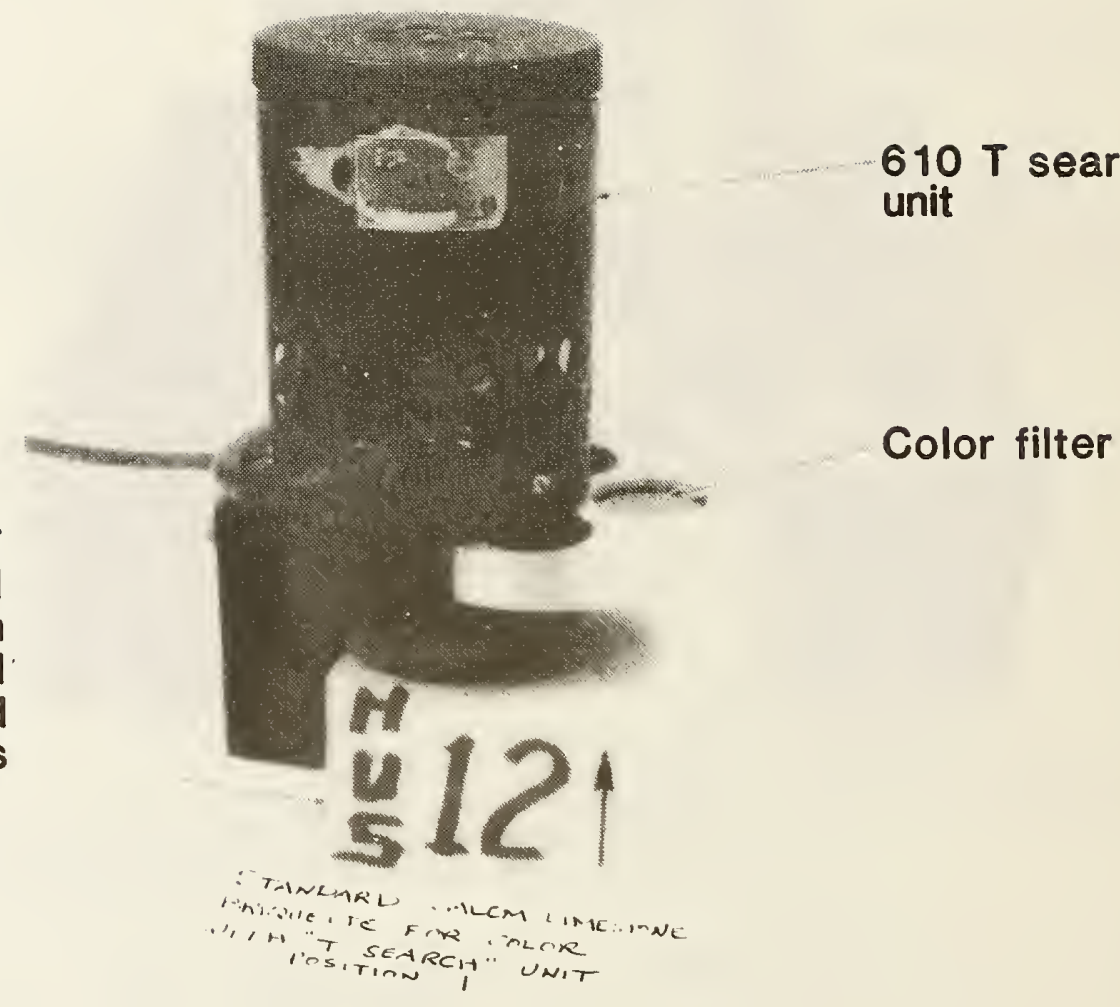

FIGURE 2. 610T Search Unit resting on stone briquette in measurement position 1. Label, HU5-12, is on a bevelled stone surface. 


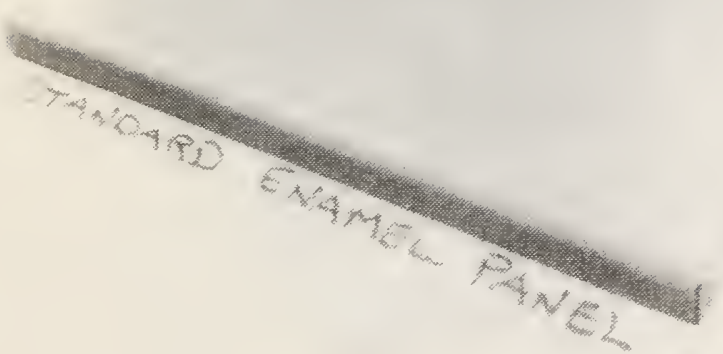

FIGURE 3. Standard reflectance enamel panel. 


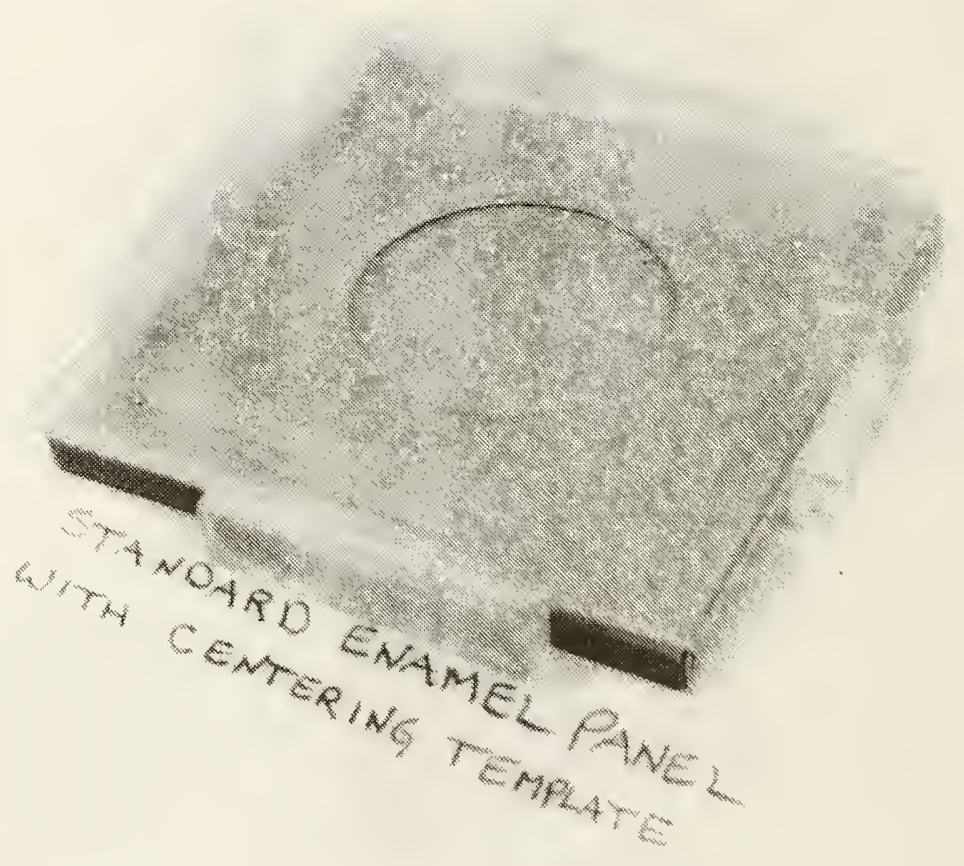

FIGURE 4. Standard reflectance enamel panel with centering template. 


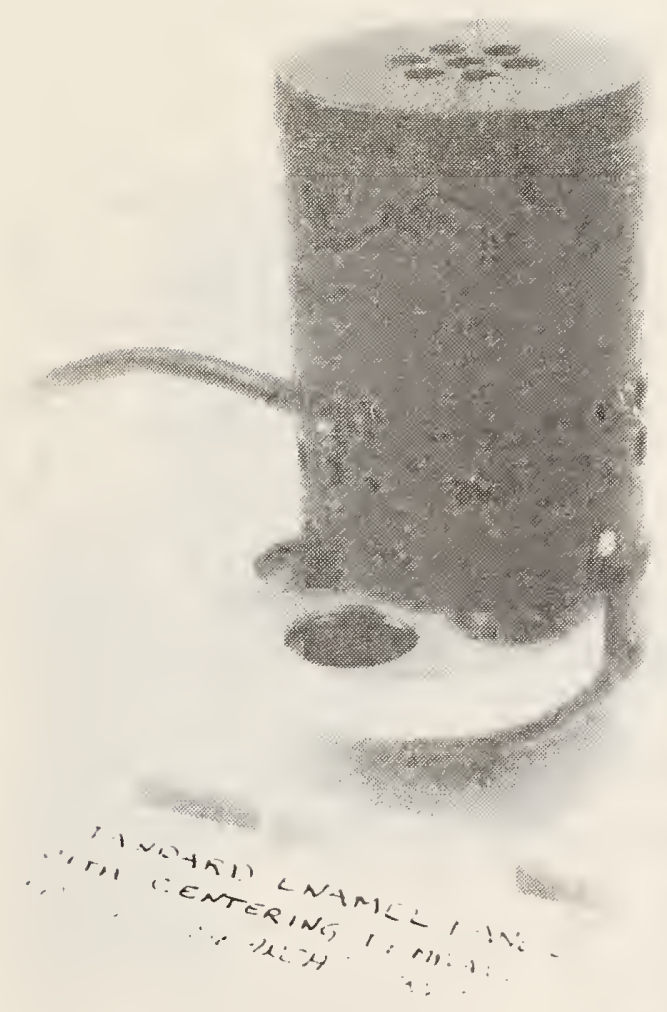

FIGURE 5. 610T Search Unit in hole in centering template. Template resting on standard reflectance enamel panel. 


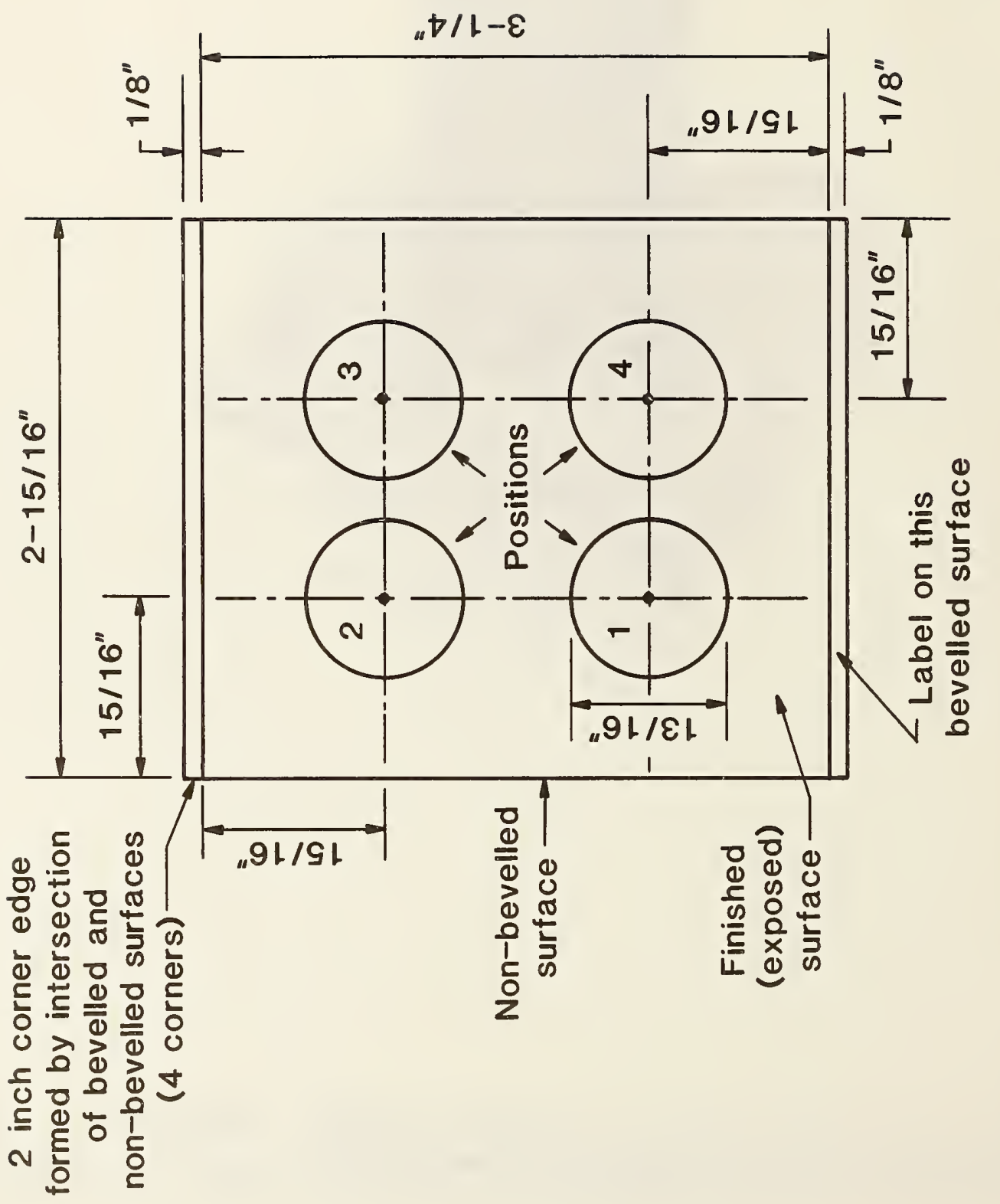

峁出

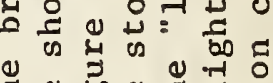

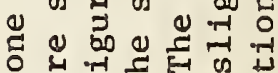
का क

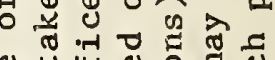
(1) ช 0 स्र 0 क

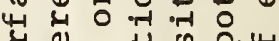

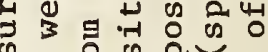

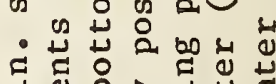

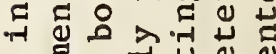

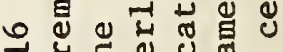
곤

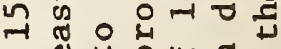
N亩部㟧 $x \rightarrow$ to $\times$ 若 5 0

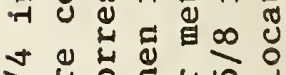

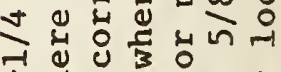

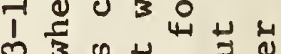
m 3 gु จิ ه 安

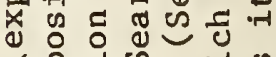

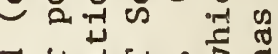

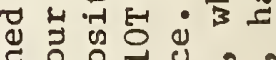

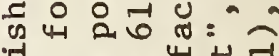

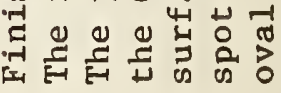

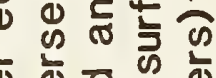
这

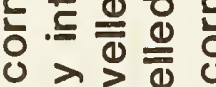
列造过 N

0 


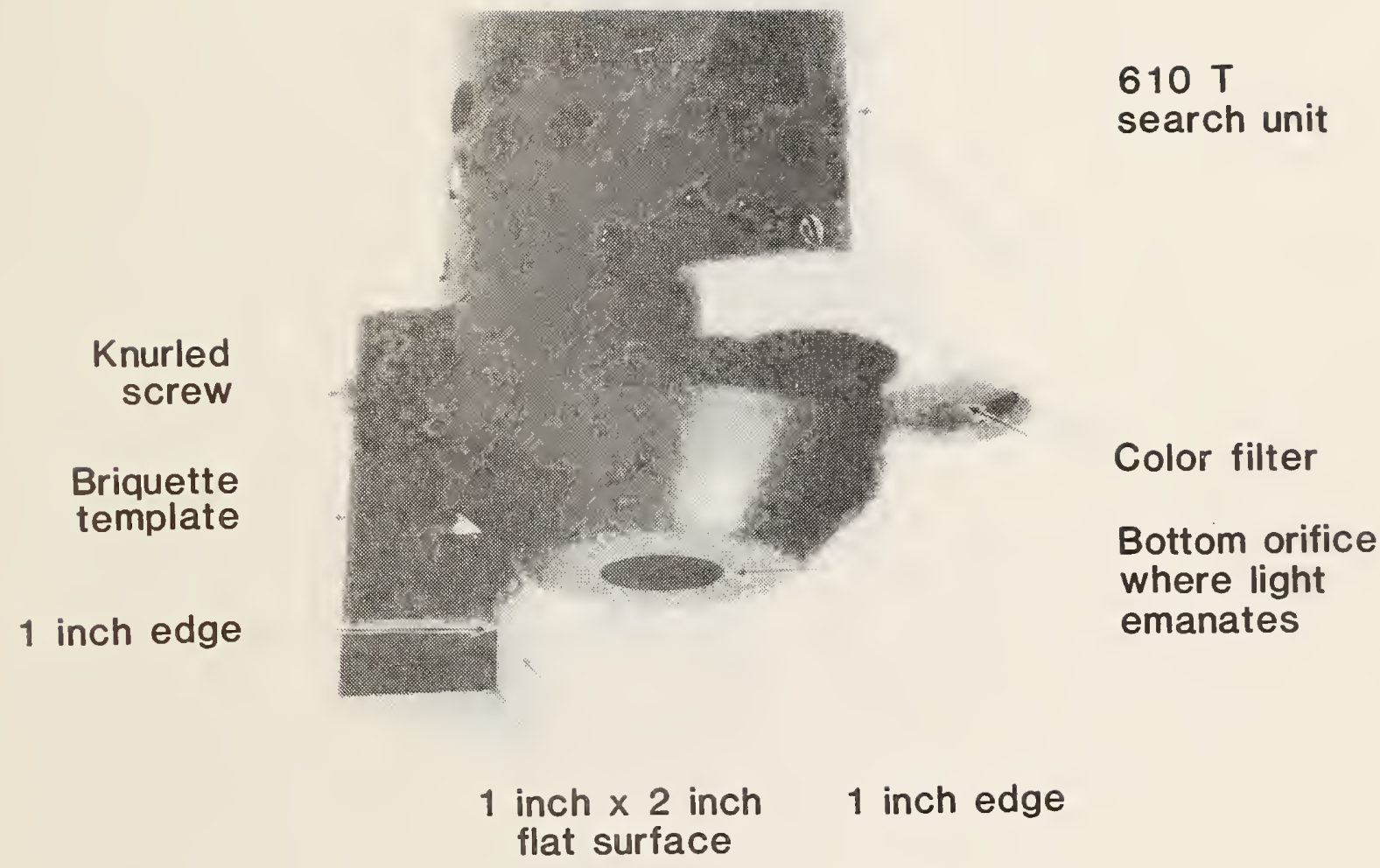

FIGURE 7. Briquette template attached to $610 \mathrm{~T}$ Search Unit. 


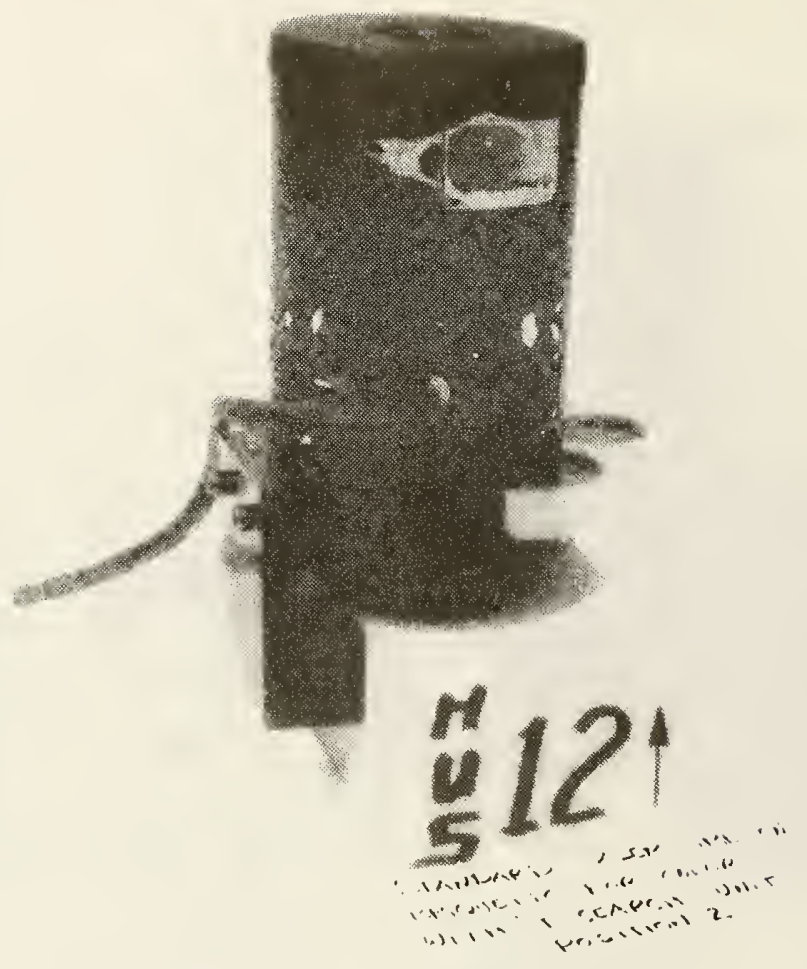

FIGURE 8. 610T Search Unit resting on stone briquette in measurement position 2 . 


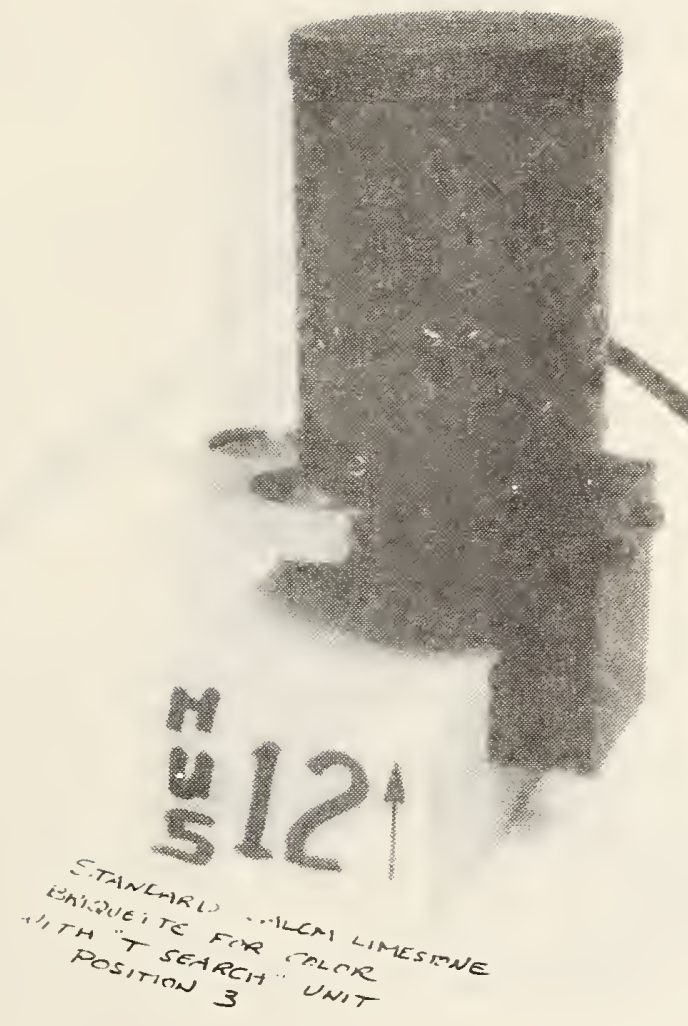

FIGURE 9. 610T Search Unit resting on stone briquette in measurement position 3 . 


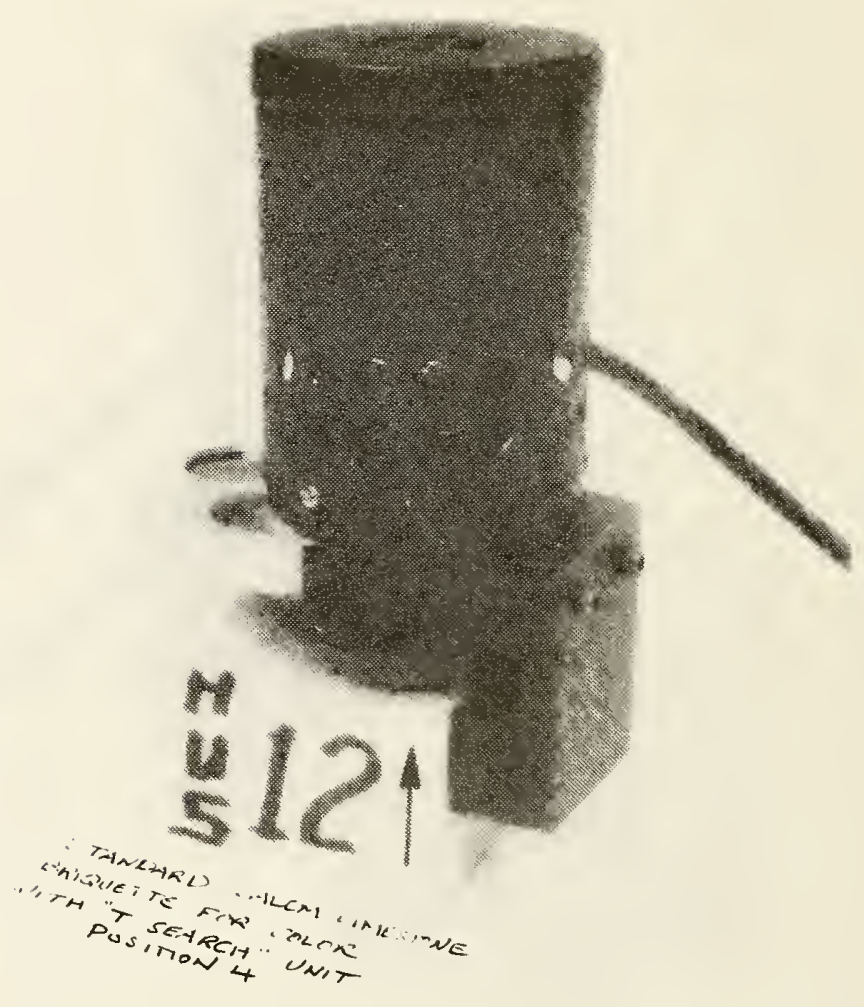

FIGURE 10. 610T Search Unit resting on stone briquette in measurement postion 4 . 


\begin{tabular}{|c|c|c|c|}
\hline $\begin{array}{r}\text { UBS. } 11 \text { AA REV OEPT. OF COMM. } \\
\text { BIBLIOGRAPHIC DATA }\end{array}$ & $\begin{array}{l}\text { 1. PUBLICATION OR } \\
\text { REPORT NO. }\end{array}$ & \\
SHEET (See instructions) & NBSIR $84-2961$ & & \\
\hline
\end{tabular}

4. TITLE AND SUBTITLE

A Procedure for Tristimulus Color Measurements on Building Stone

5. $\operatorname{AUTHOR}(S)$

lawrence I. Knab

6. PERFORMING ORGANIZATION (If joint or other than NBS, see instructions)

NATIONAL BUREAU OF STANDARDS

DEPARTMENT OF COMMERCE

WASHINGTON, D.C. 20234

\section{SPONSORING ORGANIZATION NATE AND COMPLETE ADCRESS (Etreet, CIIY. StOTE, ZIP)}

National Park Service

Contracting Policy Branch

Washington, N.C. 20240

10. SUPPLEMENTARY NOTES

Document describes a computer program; SF-185, FIPS Software Summary, is attached.

11. ABSTRACT (A 200-word or less factual summary of most significant information. If document includes a significane bibliography or literature survey, mention it here)

This report describes a procedure used to measure the color of building stone surfaces using a specific tristimulus colorimeter with three color filters. Color changes are to be monitored during a ten year or more outdoor exposure period to determine the effects of acid rain on stone color. A step-by-step procedure is provided, including equipment calibrations and checks using standard reflectance panels, equipment checks using standard stone surfaces, and color measurements of stone surfaces which are to be, or have been exposed at field sites.

12. KEY WORDS (Six to twelve entries; alphabetical order; capitalize only proper names; and separate key words by semicolons) acid rain; building stone; color; colorimeter; reflectance panels: stone; tristimulus

\section{AVAILABILITY}

Unlimited

For Official Distribution. Do Not Release to NTIS

Order From Superintendent of Documents, U.S. Government Printing Office, Washington, D.C. 20402.

[ Order From National Technical Information Service (NTIS), Springfield, VA. 22161
14. NO. OF

PRINTED PAGES

26

15. Price

\& 8.50 
